\title{
Observed Volume of Distribution
}

National Cancer Institute

\section{Source}

National Cancer Institute. Observed Volume of Distribution. NCI Thesaurus. Code C85774.

The observed volume of distribution based on the terminal phase. 